\title{
Superelastic Effect in NiTi Alloys Manufactured Using Electron Beam and Focused Laser Rapid Manufacturing Methods
}

\author{
Jan Dutkiewicz, Łukasz Rogal, Damian Kalita, Marek Węglowski, Sylwester Błacha, Katarzyna Berent, Tomasz Czeppe, Anna Antolak-Dudka, \\ Tomasz Durejko, and Tomasz Czujko
}

(Submitted August 13, 2019; in revised form April 1, 2020; published online July 11, 2020)

\begin{abstract}
Two different methods of rapid manufacturing-electron beam additive manufacturing (EBAM) and laserengineered net shaping (LENS)—were used in order to fabricate NiTi elements. Microstructure and martensitic transformation temperatures of initial materials in the form of wire or spherical powder were established. The samples fabricated using LENS technique showed martensitic transformation temperature (MTT) at $-26^{\circ} \mathrm{C}$ (represented by maximum martensite peak maximum in DSC) which was lower in comparison with raw powder. In the case of samples fabricated using EBAM, the MMT reached $-19^{\circ} \mathrm{C}$. The peaks of martensite and reverse transformations were diffuse due to differences in grain size and composition across the sample. Aging at $500{ }^{\circ} \mathrm{C}$ for $2 \mathrm{~h}$ caused not only separation of R-phase during cooling of both samples, but also formation of sharper and higher transformation peaks as well as shift of MTT to higher temperatures. Microstructural investigation showed columnar grains, near the interface of deposited element and base plate, growing perpendicular to the plate surface. The grains showed axial fiber texture $<001>$ along the growth direction. STEM micrographs revealed the presence of elongated particles enriched in Ti. Formation of Ti-rich particles during the process led to the depletion of $\mathrm{Ti}$ in the matrix and contributed to increase in MTT in comparison with initial NiTi powder. LENS-deposited sample additionally contained higher dislocation density in the austenite. Compression stress/strain curves of EBAM-deposited sample revealed deformation of martensite only, while the LENS-deposited one showed almost complete superelastic effect in compression mode up to $3 \%$.
\end{abstract}

Keywords additive manufacturing, martensitic transformation, nitinol, shape memory alloys

\section{Introduction}

Additive manufacturing (AM) has been gaining more attention in the recent years due to the possibility of fabricating metallic components of complex shapes, which are difficult to obtain using conventional techniques, simultaneously saving energy and materials (Ref 1,2). During the AM process, elements are reconstructed, based on a $3 \mathrm{D}$ CAD model, using

This article is an invited submission to JMEP selected from presentations at The XXII Physical Metallurgy and Materials Science Conference: Advanced Materials and Technologies (AMT 2019) held June 9-12, 2019, in Bukowina Tatrzańska, Poland, and has been expanded from the original presentation.

Jan Dutkiewicz, Lukasz Rogal, Damian Kalita, and Tomasz Czeppe, Institute of Metallurgy and Materials Science, PAS, 25, Reymonta St, 30-059 Krakow, Poland; Marek Weglowski and Sylwester Błacha, Lukasiewicz Research Network, 16-18 B1. Czesława Str., Gliwice, Poland; Katarzyna Berent, Academic Centre for Materials and Nanotechnology, AGH, 30, Mickiewicza Av, Kraków, Poland; and Anna Antolak-Dudka, Tomasz Durejko, and Tomasz Czujko, Military University of Technology, 2, Gen. Urbanowicza Str, 00-908 Warsaw, Poland. Contact e-mails: j.dutkiewicz@imim.pl and d.kalita@imim.pl. an additive material in the form of powder or wire which is melted using a highly focused laser or electron beam. Based on the type of the additive material, AM techniques can be divided into powder bed-like selective laser melting (SLM), powderfeed as laser engineered net shaping (LENS) and wire-feed, e.g., electron beam additive manufacturing (EBAM) (Ref 2). In the case of powder-based techniques, spherical, pre-alloyed powders are typically used (Ref 3 ), although the use of a mixture of elemental powders is also possible (Ref 4). When $\mathrm{NiTi}$ alloys are considered, one of the crucial requirements is to provide an inert atmosphere. The inert atmosphere is vital during the process due to oxidation that changes the content of titanium which can significantly affect the martensitic transformation temperatures. Interstitial impurities, like oxygen or carbon, can also reduce superelastic properties (Ref 5, 6). In the powder-feed techniques, like LENS, the process is usually conducted in a glove box under Ar atmosphere (Ref 7), while in the methods using an electron beam, like EBAM, a high vacuum has to be applied (Ref 8). In addition, the atmosphere influences the surface quality, density and mechanical properties of the final material (Ref 1,9).

The Ni-Ti alloys are well-known biomedical materials owing to their good corrosion resistance and sufficient biocompatibility in combination with the shape memory (SM) effect and superelasticity (SE) (Ref 10). However, the Young modulus of Ni-Ti alloys (about $50 \mathrm{GPa}$ ) is slightly higher than that of a human bone (10-20 GPa), which can result in stress concentration at the connection of the implant with the bone (Ref 11). One of the best solutions of this problem is to fabricate a material with introduced porosity to decrease the 
Young modulus to the values observed for bones (Ref 11, 12). However, the production of porous $\mathrm{Ni}-\mathrm{Ti}$ by conventional methods is an extremely difficult task. Extensive research has been conducted in order to fabricate porous structures by conventional sintering techniques like spark plasma sintering (SPS) or hot isostatic pressing (HIP) from pre-alloyed powders or a mixture of elemental powders (Ref 13). The superelastic properties are difficult to obtain using the powder metallurgy method due to contamination and the formation of undesirable intermetallic precipitations during sintering (Ref 13-15). In addition, these techniques are limited in the complexity of the resulting parts and in controlling the size and shape of porosity (Ref 1). Taking it into account, the use of the AM techniques seems to be an excellent way to produce complex structures from Ni-Ti alloys, especially for biomedical applications.

Porous NiTi implants have already been fabricated using the LENS technique (Ref 7). Introducing the porosity brings about the decrease of the Young modulus of the material to the value similar to that of the human cortical bone. Additionally, 2-4\% recoverable strain was obtained during the compressive test. It was observed that typical microstructures of NiTi alloys, obtained using powder techniques like SLM or LENS, consisted of columnar grains, of much higher length $(600 \mu \mathrm{m})$ in comparison with $50 \mu \mathrm{m}$ layer thickness (Ref 3). This observation was also confirmed by other authors (Ref 16), who suggested that the epitaxial grain growth took place during the process. However, Hamilton et al. (Ref 17) observed equiaxed grains with dimensions similar to the layer thickness in the microstructure of NiTi alloy, fabricated using the laserbased directed energy deposition (LDED) technique. The Nirich NiTi alloys, obtained using the AM techniques typically show a relatively high amount of high-temperature austenite B2 phase (Ref 7,18 ). High cooling rate $10^{3}-10^{5} \mathrm{~K} / \mathrm{s}$ during the laser processing results in the retention of high-temperature B2 phase at room temperature (RT). Moreover, the high cooling rate was responsible for a fine-scale dendritic grain structure. Both, LDED and SLM can produce as-built NiTi shape memory alloys (SMAs) that exhibit the complete SM recovery for about $3 \%$ macro-scale strains (Ref 17, 19). The actuation response in the as-processed condition fabricated using laser powder-bed fusion AM process is comparable with that of precipitate-free conventionally fabricated $\mathrm{NiTi}$ of a nearequiatomic composition (Ref 20). The actuation strain levels and the reversibility of the as-processed AM-NiTi SMAs are inferior to these of the conventionally produced and aged Nirich NiTi SMAs. A quite high nickel loss was observed in all of the AM techniques influencing the martensitic transformation temperatures of the fabricated materials (Ref 20, 21). The cooling rate is another significant factor affecting the phase transformation temperatures. It has been reported, that decreasing the cooling rate, increases the $\mathrm{M} \rightarrow \mathrm{A}$ transformation temperature (Ref 22). Another factor affecting the martensitic transformation temperatures is the grain size. It was confirmed that by reducing the grain size, particularly below $100 \mathrm{~nm}$, the transformation temperatures decreased (Ref 23).

Additive manufacturing of NiTi alloys is a promising research topic, due to a wide potential application of complex shape NiTi alloys as biomaterials or actuators. However, so far, only the powder based method has been extensively studied. There is no data available in the literature on AM techniques using wire, such as the EBAM method, when it comes to the mentioned materials. It offers a high efficiency and good protection against oxidation during the process due to the application of a high vacuum chamber. Another advantage of this procedure is that the wire usually contains less oxygen than the powder which can affect the martensitic transformation temperature of NiTi (Ref 5, 6). Therefore, the aim of the present paper is to compare the microstructure, martensitic transformation behavior and superelastic properties of Ni-rich NiTi alloys fabricated using the well-known LENS technique and new EBAM technique, which applies wire as the additive material. The effect of post deposition aging was also analyzed in order to determine the ability of changing the martensitic transformation temperatures during cooling or aging in additively manufactured NiTi alloys, similarly to the heat treatment performed on conventional materials (Ref 24).

\section{Experimental}

\subsection{Materials Preparation}

In the present study two different AM methods-EBAM and LENS were used in order to fabricate components from Ni$\mathrm{Ti}$ alloys. The additive material in the form of wire was applied in the EBAM process. The wire was melted by an electron beam and created a melt pool on the surface of the deposited element. The process was performed using electron beam welding system XW150:30/756 (Cambridge Vacuum Engineering Ltd.) with the maximum power of the beam $30 \mathrm{~kW}$. The device was equipped with a wire feeder inside the vacuum chamber. The 1-mm-thick wire with the chemical composition of 50.97 at. $\% \mathrm{Ni}, 0.22$ at.\% max C, Ti balance, also delivered by SMATEC company, Belgium, was used for deposition. The wire was delivered after heat treatment to modify transformation temperatures. The composition of the sheet substrate delivered also by SMATEC Company, Belgium was 50.74 at.\% Ni, 0.12 at.\% $\max \mathrm{C}, 0.11$ at.\% O, Ti balance. Based on preliminary studies the set of following parameters was applied during the fabrication process: accelerating voltage $60 \mathrm{kV}$, beam current $15 \mathrm{~mA}$, feeding angle $30^{\circ}$, wire feed speed $1000 \mathrm{~mm} / \mathrm{min}$ and travelling speed $2000 \mathrm{~mm} / \mathrm{min}$. Rectangular samples with dimensions of $5 \times 10 \times 45 \mathrm{~mm}$ were obtained.

In the case of LENS technique the material in the form of spherical powder was used. During deposition the powder was injected through the nozzles into the melt pool formed on the deposit surface by a highly focused laser beam. The deposition process was performed using the LENS MR-7 system (Optomec, USA) equipped with a 500-W fiber laser. Spherical, gas atomized powder, with particle size in the range of $45-$ $115 \mu \mathrm{m}$ and the chemical composition: 50.08 at.\% $\mathrm{Ni}, 0.01$ at. $\% \mathrm{C}, 0.10$ at.\% O, Ti balance was used. In order to obtain cylindrical samples with $20 \mathrm{~mm}$ diameter and the height of $10 \mathrm{~mm}$, the following parameters were used: laser power $400 \mathrm{~W}$, laser spot diameter $1.2 \mathrm{~mm}$, working table feed rate $10 \mathrm{~mm} / \mathrm{min}$, powder flow rate $15 \mathrm{~g} / \mathrm{min}$, and single layer thickness $0.30 \mathrm{~mm}$. Moreover, the process was performed in the chamber under purified argon atmosphere $\left(\mathrm{O}_{2}\right.$ and $\mathrm{H}_{2} \mathrm{O}<$ $10 \mathrm{ppm})$. Aging at $500{ }^{\circ} \mathrm{C}$ for $2 \mathrm{~h}$ was performed, as an example of a typical heat treatment for Ni-rich $\mathrm{Ni}-\mathrm{Ti}$ alloys (Ref 25), for the raw materials and additive manufactured samples. The materials were analyzed in the as-deposited and aged states. 


\subsection{Material Characterization}

The microstructural observations of fabricated samples were conducted using a scanning electron microscope (SEM) FEI Versa 3D and a Leica DMIRM optical microscope, on previously etched samples using a Kroll's reagent. EBSD analysis was performed with EDAX Hikari CCD-based detector and a TSL OIM Data collection software version 7.0. The detailed microstructural studies were performed using a transmission electron microscope (TEM) Tecnai FEG G2 F20 Super Twin, equipped with an integrated EDAX Apollo XP energydispersive X-ray spectrometer (EDS). The thin foils for TEM observations were prepared by electropolishing $100-\mu \mathrm{m}$-thick

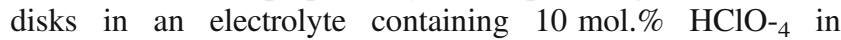
methanol (voltage $20 \mathrm{~V}$, temperature $-20{ }^{\circ} \mathrm{C}$ ). The compression tests were performed at a Shimadzu Autograph AG-X plus testing machine at strain rate $10^{-3} 1 / \mathrm{s}$. The samples for mechanical tests, in the form of cylinders with the diameter of $4 \mathrm{~mm}$ and the height of $6 \mathrm{~mm}$, were prepared using an electrical discharge machine. The differential scanning calorimetry (DSC, Q1000 TA Instruments) method was used in order to determine the temperatures of phase transformations. The applied heating/cooling rate was $20^{\circ} \mathrm{C} / \mathrm{min}$.

\section{Results and Discussion}

\subsection{Powder and Wire Feedstock Characterization}

Figure 1a shows an optical micrograph of the cross section of spherical Ni-Ti powder particle used in the LENS process. The average size of powder particles was $\sim 87 \mu \mathrm{m}$ and they consisted of dendritic grains with size in the range of 10 $40 \mu \mathrm{m}$. The DSC heating and cooling curves of the powder in the as-supplied and aged at $500{ }^{\circ} \mathrm{C}$ for $2 \mathrm{~h}$ states are presented in Fig. 1b. The following martensitic and reverse transformation temperatures were determined: martensite start $\left(M_{\mathrm{s}}\right)$, martensite finish $\left(M_{\mathrm{f}}\right)$, austenite start $\left(A_{\mathrm{s}}\right)$ and austenite finish $\left(A_{\mathrm{f}}\right)$. In addition two further temperatures were calculated $-M_{p}$ (martensite peak) and $A_{\mathrm{p}}$ (austenite peak), which represented the temperatures corresponding to the maximum rate of martensitic and reverse transformations. The curves obtained for powder in as-supplied state showed diffuse maxima of martensitic and reverse transformations with the following characteristic temperatures: $M_{\mathrm{s}}=17.9^{\circ} \mathrm{C}, M_{\mathrm{f}}=-21.3^{\circ} \mathrm{C}$, $A_{\mathrm{s}}=19.5{ }^{\circ} \mathrm{C}, A_{\mathrm{f}}=45^{\circ} \mathrm{C}, M_{\mathrm{p}}=2.5^{\circ} \mathrm{C}, A_{\mathrm{p}}=35.3{ }^{\circ} \mathrm{C}$. Therefore, they should show a partially martensitic/austenitic structure at RT, which was confirmed by the x-ray diffraction analysis and by other authors (Ref 26,27$)$. After aging the powder at $500{ }^{\circ} \mathrm{C}$ for $2 \mathrm{~h}$ a small shift of $M_{\mathrm{p}}$ and $A_{\mathrm{p}}$ temperatures toward higher temperatures can be easily seen, similarly as observed in (Ref 28, 29). The complete transformation temperatures values are presented in Table 1. The aging process affected also the shape of peaks connected with martensitic and reverse transformations-peaks after aging were much sharper and higher. An additional peak observed in the cooling curve of the aged sample is connected with R-phase transition, which is commonly observed in aged Ni-rich Ni-Ti alloys (Ref 28, 30).

Figure 2 shows SEM micrographs of the longitudinal (a) and transverse (b) sections of NiTi wire in the as-supplied state, showing equiaxed grains with size in the range of $5-20 \mu \mathrm{m}$. The wire in the as-supplied state exhibits only a weak and diffuse peak from the reverse transformation in the temperature range from -87.1 to $5.2{ }^{\circ} \mathrm{C}$. The peak from the martensitic transformation was not observed in the analyzed temperature range, which suggested that the transformation took place below $-100{ }^{\circ} \mathrm{C}$. These results are in agreement with the literature data showing that the $M_{s}$ temperature for NiTi alloys containing 51 at. $\%$ of $\mathrm{Ni}$ is about $-110^{\circ} \mathrm{C}(\operatorname{Ref} 31)$. Therefore, the observed martensitic plates in the microstructure of the wire (Fig. 2a and Fig. 2b) occur to be stress-induced martensite, formed during drawing of the wire. Aging performed at $500^{\circ} \mathrm{C}$ for $2 \mathrm{~h}$ led to a shift of the peaks from the martensitic and the reverse transformation toward higher temperatures. The effect connected with the R-phase transformation was observed in the temperature range from -5.5 to $10.5^{\circ} \mathrm{C}$. The lower transformation temperatures in the case of the wire, both in the as-supplied and aged states, were associated with higher $\mathrm{Ni}$ content of 50.97 at.\% and 50.08 at. $\%$ in the powder.

\subsection{Effect of the Deposition Process}

Figure 3 shows a photograph of LENS (Fig. 3a) and EBAM (Fig. 3b) deposited NiTi elements in the shape of a tube and a rectangular prism, respectively. Both were deposited on NiTi sheets to eliminate the composition change due to mutual diffusion. Different geometries of samples resulted from different forming possibilities of the both applied techniques. The thin-walled structures were typically obtained using the LENS technique due to the application of powder as additive material. Therefore, in the presented work the tube $20 \mathrm{~mm}$ in diameter and $10 \mathrm{~mm}$ high with 1-mm-thick wall was chosen as the representative geometry. In the case of EBAM method, 1mm-thick wire was used for deposition and much less complicated shapes could be obtained in comparison with the LENS process. In the present work several layers were deposited in order to form a rectangular shape of the sample $5 \times 10 \times 60 \mathrm{~mm}$. Both elements were investigated to analyze their microstructure, martensitic transformation temperatures and superelastic behavior.

Figure 4 shows optical micrographs of the microstructure of NiTi elements manufactured using LENS and EBAM methods, respectively. The images of the interface between the deposited material and the substrate were recorded. In both cases the elongated grains, perpendicular to the surface of substrate can be observed. Their morphology indicates that, an epitaxial grain growth in the building direction takes place during the deposition. This observation was also confirmed by other authors, who analyzed the microstructure of NiTi elements obtained using powder AM techniques (Ref 32, 33). It is typical of the AM process that the penetration depth of a laser or an electron beam is larger than the thickness of the deposited layer, therefore part of the beam energy is used to re-melt the surface layer of the element. Due to a high thermal gradient in the created melt pool, conditions for the epitaxial growth of the columnar layer appear at the bottom of the pool (Ref 33). The EBSD analysis was conducted in order to determine the crystallographic texture of the deposited elements and the orientation dependence between the grains in the substrate and the deposited layers.

Figure 5a shows the inverse pole figure (IPF) maps of NiTi fabricated using the LENS method, taken of the area of the interface between the substrate and deposited layers. It is important to notice that the width of the columnar grain is controlled by the size of the equiaxed grains in the substrate. 

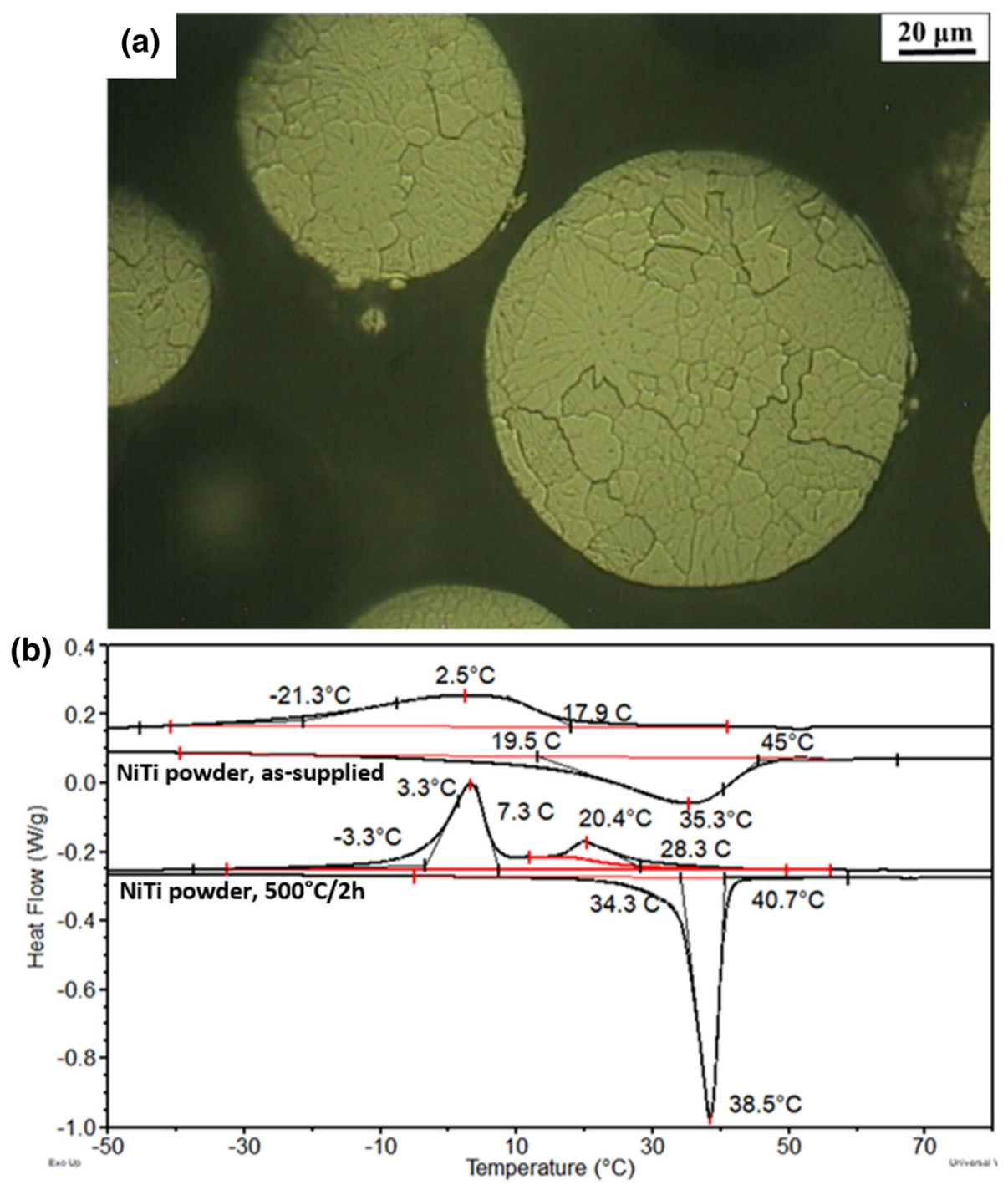

Fig. 1 (a) Optical micrograph of the powder used to produce NiTi elements using LENS method, (b) DSC cooling and heating curves of the powder showing diffuse maxima of martensitic and reverse transformations. Below are DSC curves of the powder after 2-hour annealing at $500{ }^{\circ} \mathrm{C}$ with small shift of transformation temperatures toward higher temperature range

Table 1 Transformation temperatures for investigated materials obtained using DSC technique

\begin{tabular}{|c|c|c|c|c|c|c|}
\hline \multirow[b]{2}{*}{ Material } & \multicolumn{6}{|c|}{ Temperature, ${ }^{\circ} \mathrm{C}$} \\
\hline & $M_{s}$ & $M_{f}$ & $A_{s}$ & $A_{f}$ & $M_{p}$ & $A_{p}$ \\
\hline NiTi powder, as-supplied & 17.9 & -21.3 & 19.5 & 45.0 & 2.5 & 35.3 \\
\hline NiTi powder, $500^{\circ} \mathrm{C} / 2 \mathrm{~h}$ & -0.2 & -3.3 & 34.3 & 40.7 & 3.3 & 38.5 \\
\hline NiTi wire, as-supplied & $\cdots$ & $\cdots$ & -87.1 & 4.0 & $\cdots$ & -53.9 \\
\hline $\mathrm{NiTi}$ wire, $500^{\circ} \mathrm{C} / 2 \mathrm{~h}$ & -30.3 & -48.4 & 8.9 & 31.0 & -37.9 & 13.3 \\
\hline LENS element, as-deposited & -20.5 & -45.4 & -21.9 & 10.2 & -26.2 & -0.5 \\
\hline LENS element, $500^{\circ} \mathrm{C} / 2 \mathrm{~h}$ & -6.2 & -18.8 & 30.4 & 40.6 & -12.7 & 34.8 \\
\hline EBAM element, as-deposited & 2.2 & -46.6 & -17.8 & 30.7 & -19.2 & 12.2 \\
\hline EBAM element, $500^{\circ} \mathrm{C} / 2 \mathrm{~h}$ & -10.4 & -42.6 & 22.8 & 43.1 & -15.4 & 31.7 \\
\hline
\end{tabular}

The results confirmed that during the deposition process, the epitaxial crystallization of columnar grains, proceeds in the heat flux direction. Figure 5b shows the corresponding (001), (110), and (111) pole figures (PF) of the NiTi austenite phase, from the area of the deposited material using the LENS technique. This PF shows that NiTi austenite grains in the deposited material show fiber texture in the $<111>$ along the growth direction, similarly like that described for the SLM Ni50.2Ti 

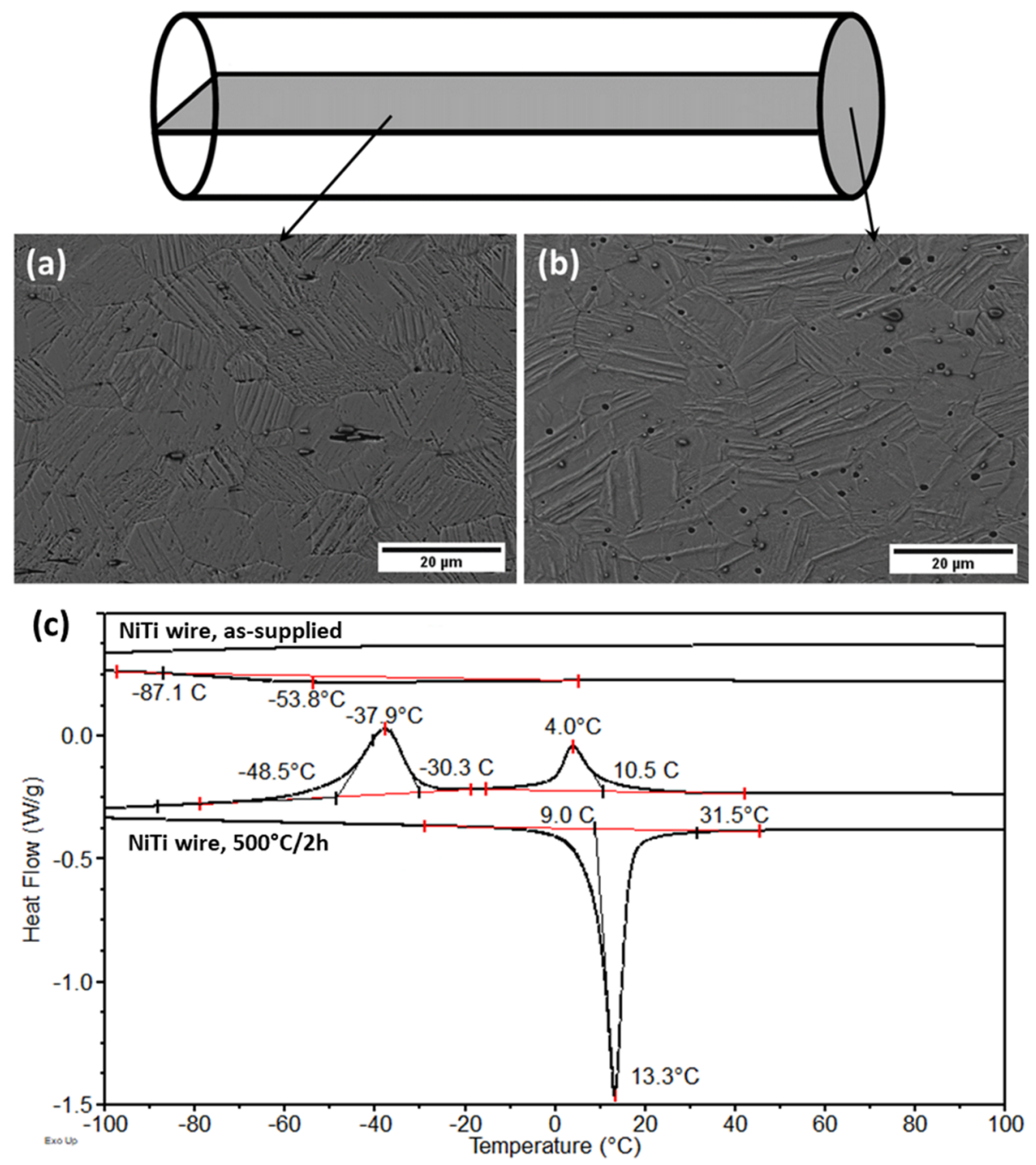

Fig. 2 SEM micrographs of the wire with marked micrograph places for imaging (a) longitudinal section and (b) cross-section, (c) DSC cooling and heating curves of the wire in as-supplied state (upper curves) and after annealing at $500{ }^{\circ} \mathrm{C}$ for $2 \mathrm{~h}$ (lower curves)

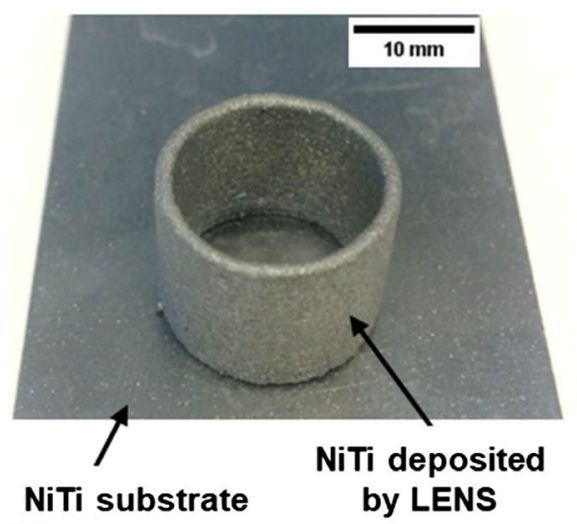

(a)

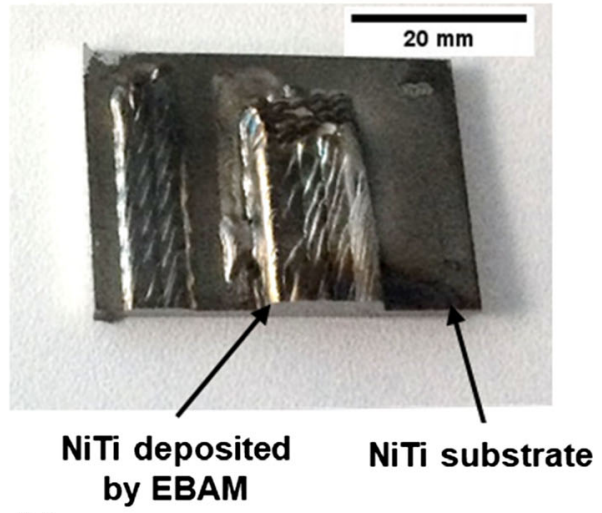

(b)

Fig. 3 Photographs of (a) LENS-deposited NiTi tube, (b) rectangular prism obtained with EBAM method

samples, in which higher number of oriented grains along the heat flow direction $<111>$ was observed (Ref 1 ).

Figure 6 shows DSC curves of NiTi alloy obtained using LENS (a) and EBAM (b) techniques in the as-deposited and aged states. In the case of the element obtained using the LENS technique, in the as-deposited state, the martensitic and reverse transformation temperatures were shifted to much lower temperatures, e.g., $M_{\mathrm{p}}$ from $2.5^{\circ} \mathrm{C}$ for the powder to $-26.2^{\circ} \mathrm{C}$ for the element in as-deposited state. The full temperature characteristic of the transformations is contained in 

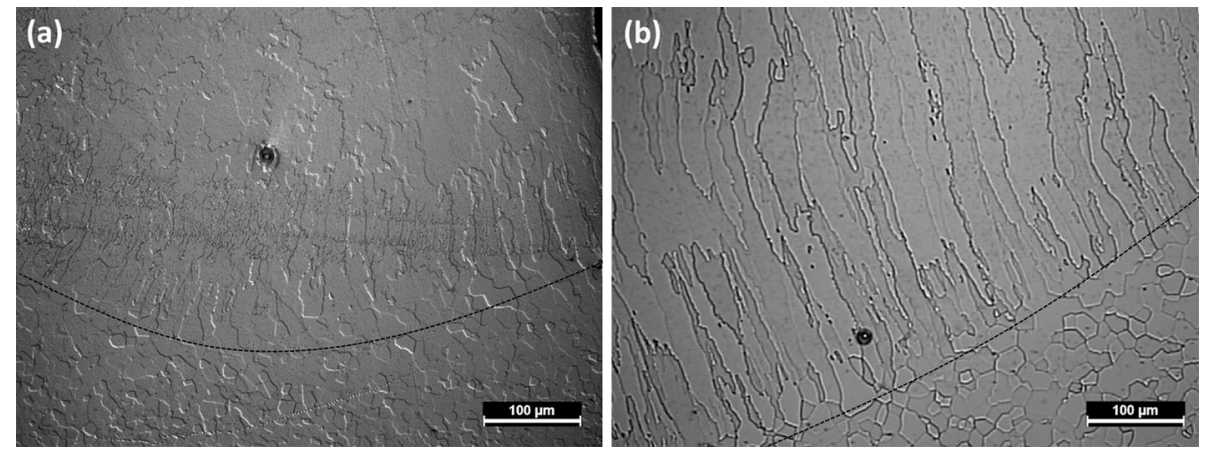

Fig. 4 Optical micrograph show the interface (dashed line) between the substrate (equiaxed grains) and deposited material using (a) LENS and (b) EBAM methods

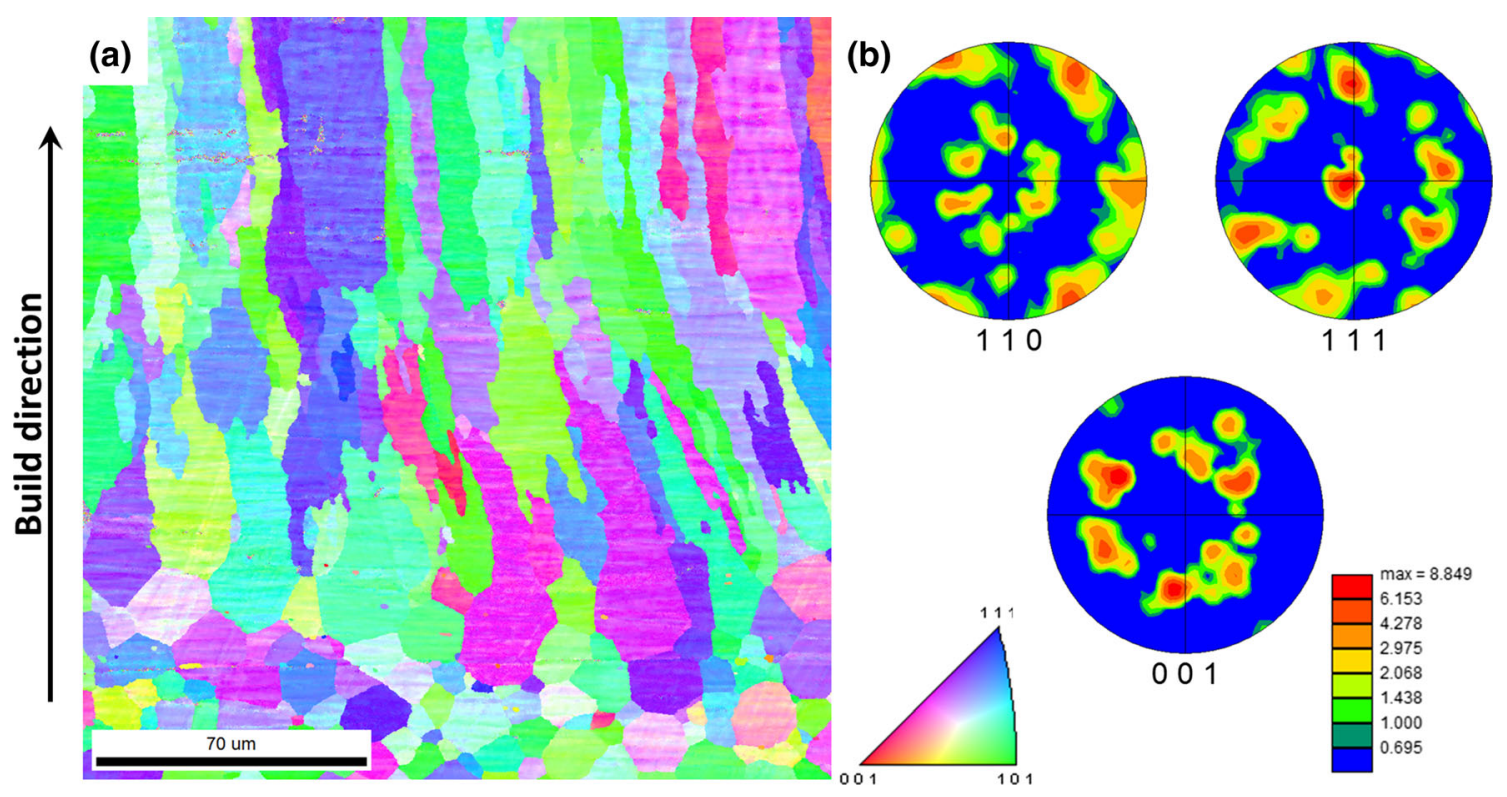

Fig. 5 IPF map of NiTi fabricated using LENS technique (a) and the corresponding (001), (100), and (110) pole figures (b) taken at cross section (Z-plane perpendicular to the build direction) from area of deposited material

Table 1. This observation is rather different from what was previously observed in LENS deposited samples, where an increase in martensite transformation temperature (MTT) usually occurred (Ref 29, 30), being attributed to a Ni loss. In the case of this study, the precipitation of Ti-rich particles like titanium oxides $\left(\mathrm{Ti}_{4} \mathrm{Ni}_{2} \mathrm{O}\right)$ or $\mathrm{Ti}_{2} \mathrm{Ni}$ precipitates, during the solidification process, that can lower MTT, seems to be a more suitable mechanism (Ref 28). Aging at $500{ }^{\circ} \mathrm{C}$ for $2 \mathrm{~h}$ resulted in a shift of the transformation temperatures to higher temperatures, in comparison with as-deposited material $\left(M_{\mathrm{p}}\right.$ from -26.2 to $12.7^{\circ} \mathrm{C}$ and $A_{\mathrm{p}}$ from $-0.5^{\circ} \mathrm{C}$ to $\left.34.8^{\circ} \mathrm{C}\right)$. A similar effect was observed earlier by Honma (Ref 8 ) after aging of Ni-rich NiTi alloys at a similar temperature range. During the aging process of Ni-rich NiTi alloys at this temperature range $\mathrm{Ni}$-rich precipitations, like $\mathrm{Ni}_{4} \mathrm{Ti}_{3}$, are formed and, as result, the concentration of $\mathrm{Ni}$ in the matrix decreases and transformation temperatures increase (Ref 34, 35). An additional peak can be observed on the cooling curve of the aged material, which is probably connected with the Rphase formation, frequently observed in the aged NiTi alloys (Ref 23, 29).
Figure 6b shows DSC curves of the EBAM deposited material in the as-deposited and aged states. For the sample in the as-deposited state, a broad diffuse peak is observed, with maximum at $-19.2{ }^{\circ} \mathrm{C}$, which is a result of non-homogeneity of the deposited sample with respect to the chemical composition, as well as the grain size, as suggested in (Ref 29). Aging at $500{ }^{\circ} \mathrm{C}$ for $2 \mathrm{~h}$ caused the shift of the temperatures of martensitic and reverse transformations toward higher temperatures $-M_{\mathrm{p}}$ from -19.2 to $-15.4{ }^{\circ} \mathrm{C}$ and $A_{\mathrm{p}}$ from 12.2 to $31.7{ }^{\circ} \mathrm{C}$, but those changes were not as high as in the LENS deposited material. In addition, similarly to the LENS fabricated material, a peak coming from the R-phase formation was observed in the cooling curve of the aged sample. In both materials, the peaks became narrower and higher after aging. The changes in the shape of the martensitic and reverse transformation peaks could be connected with residual stresses in the as-fabricated samples. It is well known that elements fabricated using AM techniques contain a high level of residual stresses due to the rapid solidification and thermal cycles during the deposition process (Ref 36, 37). Chrobak et al. showed, that, with increasing the degree of plastic deformation of NiTi 

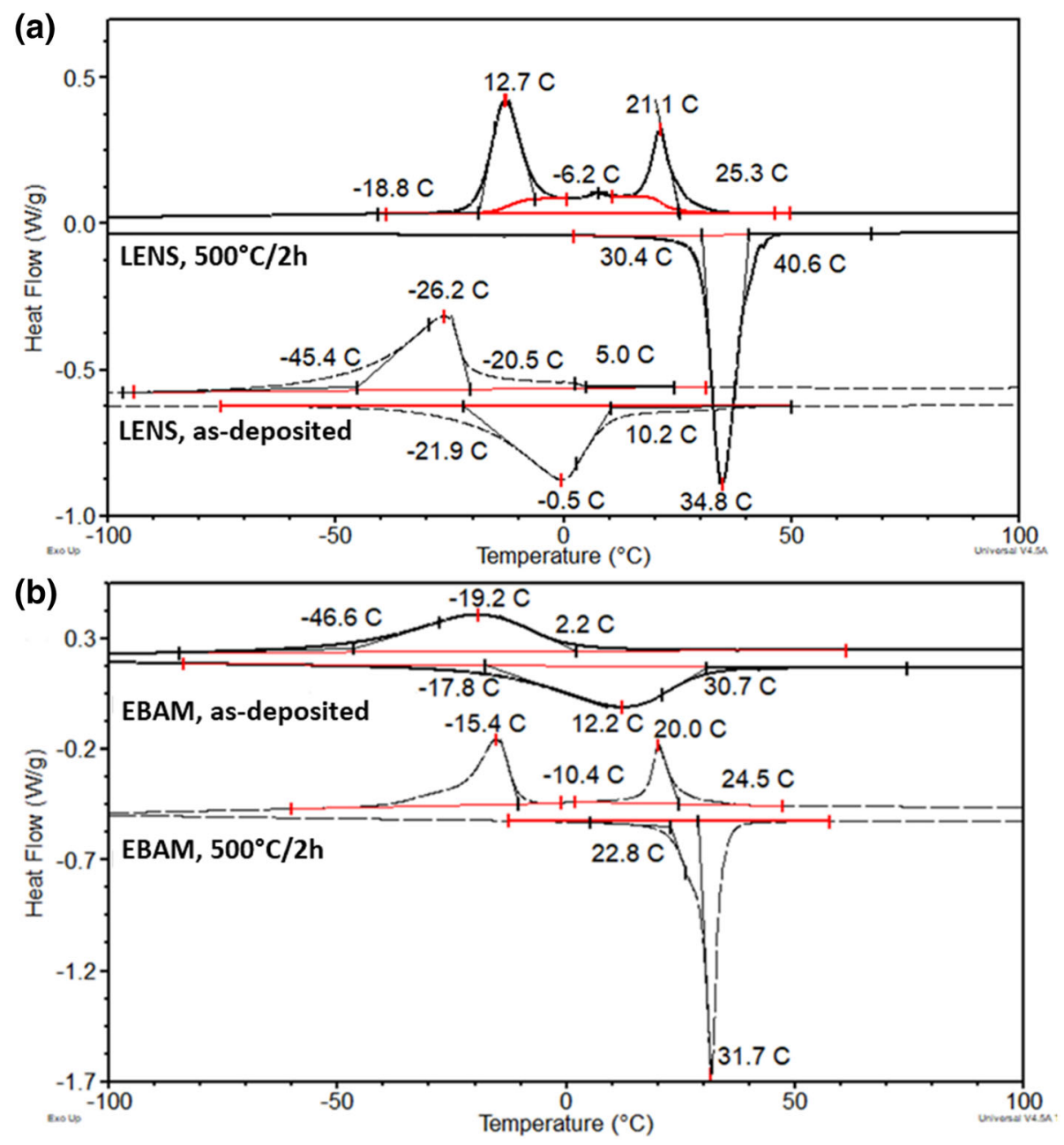

Fig. 6 DSC curves from NiTi products: (a) the as-deposited with LENS method (lower curve) and after annealing at $500{ }^{\circ} \mathrm{C} / 2 \mathrm{~h}$ (upper curve), (b) EBAM wire directly after the deposition (upper curve) and heat treated at $500{ }^{\circ} \mathrm{C}$ for $2 \mathrm{~h}$ (lower curve)

alloys, the temperature of martensitic transformation lowered and the DSC peaks connected with this transformation changed their shape to more diffuse (Ref 38 ). The aging process resulted in narrower and higher peaks because of the recovery and precipitation processes (Ref 39). In the case of the superelastic behavior, the most important value is $A_{f}$ temperature. The full superelastic deformation can only take place in the temperature range above $A_{f}$, as an effect of the formation of martensite phase during loading and reverse transformation to the austenite during unloading (Ref 34). In the case of the aged materials fabricated using LENS and EBAM process, the $A_{f}$ temperatures were $40.6{ }^{\circ} \mathrm{C}$ and $37.1{ }^{\circ} \mathrm{C}$, respectively, which suggested that only a partial superelastic effect can be observed at RT.

The TEM studies were performed in order to determine the type of martensite in the studied NiTi alloy deposited using AM techniques, as well as the type of precipitations formed during the fabrication process. Figure 7 presents a scanning transmission electron microscopy (STEM) micrograph of NiTi sample fabricated using LENS technique in the as-deposited state. Fine martensite plates can be observed in the microstructure together with elongated particles. The chemical composition (Table 2) shows that these particles (points 2 and 3 in Fig. 7) are enriched

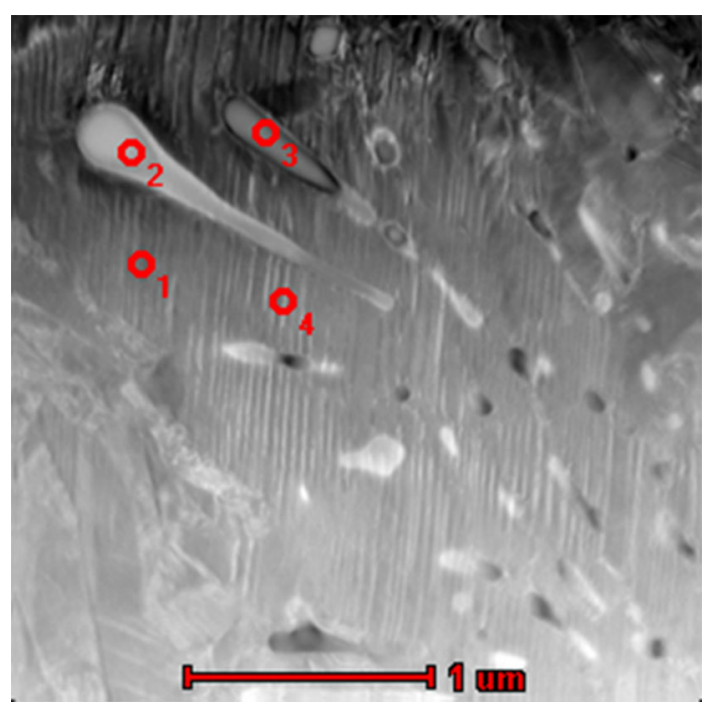

Fig. 7 A STEM micrograph of LENS-deposited NiTi. The results of EDS chemical analysis, in marked places (1-4), are presented in Table 2 
in $\mathrm{Ti}$, which resulted in an increase in concentration of $\mathrm{Ni}$ in the matrix (points 1 and 4).

Figure 8 shows a TEM bright field (BF) micrograph of the NiTi sample fabricated using LENS technique in the asdeposited state, showing the interface between fine plates of B19' martensite phase and the B2 austenite. Twins within the martensitic area with a twinning plane close to (011) B19' are clearly visible in the micrograph and the selected area electron diffraction pattern (SAEDP) shown as an insert. Frequent dislocations can be seen within the austenite affecting martensite transformation temperatures. It is well known that growth of dislocation density decreases the $M_{s}$ temperature (Ref 40). The crystallographic relationship 100 B2 \| [100] B19' and (001) B2\| (011) B19' results from the SAEDP solution. Figure 9 shows a TEM micrograph of the sample deposited on the NiTi substrate using EBAM method with the interface between the B2 austenite and B19' martensite. It is similar to the LENS sample, where (101) B2 were parallel to (100) B19', although the other component was different [010] B19' $\|$ [14-1] B2. The dislocation density in the case of the material fabricated using EBAM method was much lower in comparison with the samples obtained by LENS technique, most probably due to higher energy used and thicker samples causing lower cooling rate, therefore the contribution of that factor to the martensitic transformation temperatures was lower.

Figure 10 shows the compressive stress-strain loading/ unloading curves for the samples deposited using LENS

Table 2 Chemical composition, measured by EDS, of areas marked in Fig. 7

\begin{tabular}{lcc}
\hline \multirow{2}{*}{ Point of analysis } & \multicolumn{2}{c}{ Chemical composition } \\
\cline { 2 - 3 } & Ti, at.\% & Ni, at.\% \\
\hline 1 & 49.6 & 50.4 \\
2 & 55.2 & 44.8 \\
3 & 57.5 & 42.5 \\
4 & 46.7 & 53.3 \\
\hline
\end{tabular}

technique and aged at $500{ }^{\circ} \mathrm{C}$ for $2 \mathrm{~h}$. The compression tests were performed in cyclic mode with increasing strain by $1 \%$ in each cycle until the permanent deformation occurs. The presented curves represent the maximum strains which were fully or at least mostly recoverable. All samples underwent only partial strain recovery. The material in the as-deposited state revealed a good strain recovery (about 3\%), which is in agreement with DSC results showing $A_{f}$ temperature below the deformation temperature (RT). The recoverable strain decreased to about $1.5 \%$ in the case of aged material, as a result of shift of $A_{f}$ toward a higher temperature. Therefore, in order to determine the superelastic behavior above the $A_{f}$ temperature, the compression test was performed at $51{ }^{\circ} \mathrm{C}\left(10{ }^{\circ} \mathrm{C}\right.$ above $\left.A_{f}\right)$. This result shows almost complete strain recovery near $4 \%$.

Figure 11 shows the results of the compression test of asdeposited and aged samples at $500{ }^{\circ} \mathrm{C} / 2 \mathrm{~h}$ prepared using the EBAM technique. Both compression curves performed at RT show a typical martensite deformation curves without visible superelastic effect, as a result of deformation above the $M_{f}$ temperature. The $A_{\mathrm{f}}$ temperature was located slightly above RT, therefore the stress-induced martensitic transformation could take place during the test. It is important to note, that a low critical stress for the induction of martensite transformation is associated with $M_{\mathrm{s}}$ temperature, which is close to the test temperature [29). The compression test performed at $53{ }^{\circ} \mathrm{C}\left(10{ }^{\circ} \mathrm{C}\right.$ above $\left.A_{\mathrm{f}}\right)$ shows almost complete strain recovery up to $4 \%$.

The obtained results of recoverable strains are lower in comparison with conventionally fabricated NiTi alloys (up to $8 \%$ ) (Ref 12). However, dealing with the material fabricated using the LENS technique, in the as-deposited state, the results are similar to the literature data. Saedi et al. (Ref 41) reported $3 \%$ recoverable strain in the as-deposited NiTi using the SLM technique, similarly to Moghaddam et al., (Ref 42) who observed recoverable strains between 3.8 and $2.7 \%$ in the SLMdeposited NiTi, depending on scanning strategy. These results can be further improved by applying an appropriate heat treatment, e.g., Saedi et al. (Ref 41) showed an increase in recoverable strain from 3 to $5.5 \%$ by solutionizing and aging at $450{ }^{\circ} \mathrm{C}$. In the presented work, the applied heat treatment allowed to obtain about $4 \%$ recoverable strain in the case of

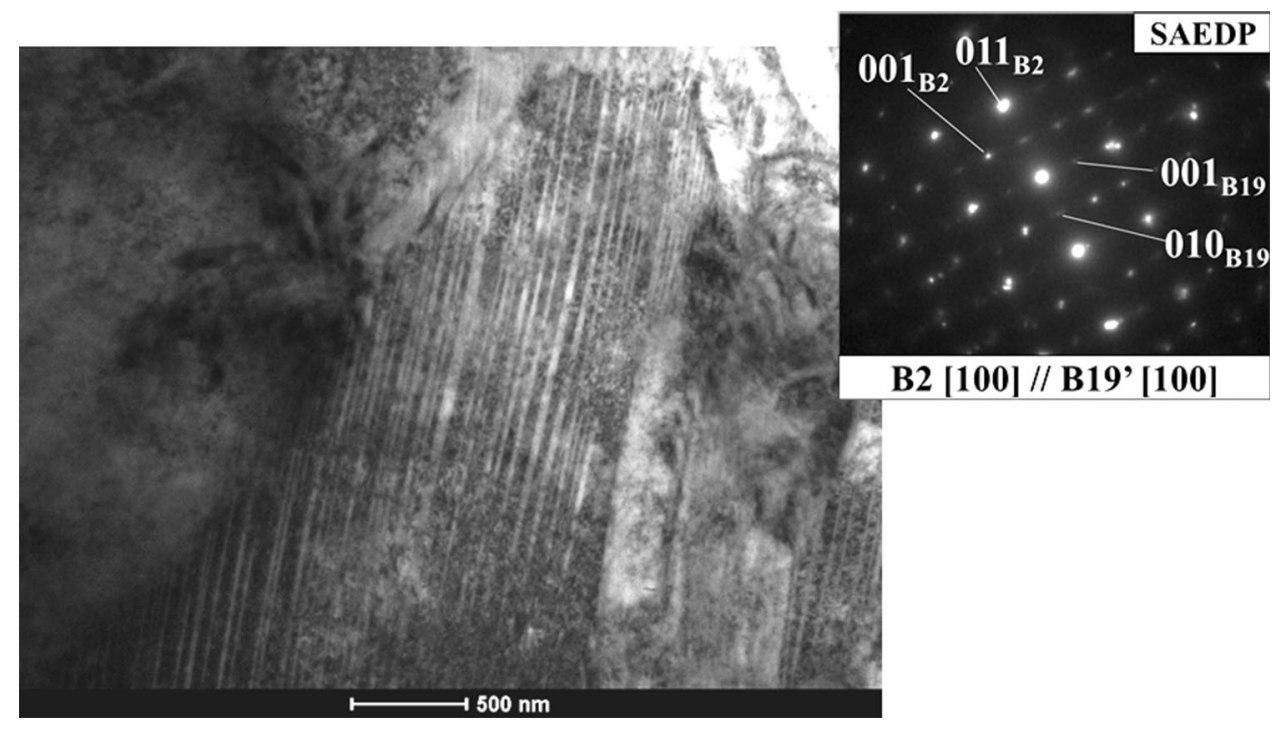

Fig. 8 BF-TEM image taken of as-deposited NiTi obtained with LENS method and SAEDP showing crystallographic relationship between parent $\mathrm{B} 2$ austenite and $\mathrm{B} 19^{\prime}$ martensite 


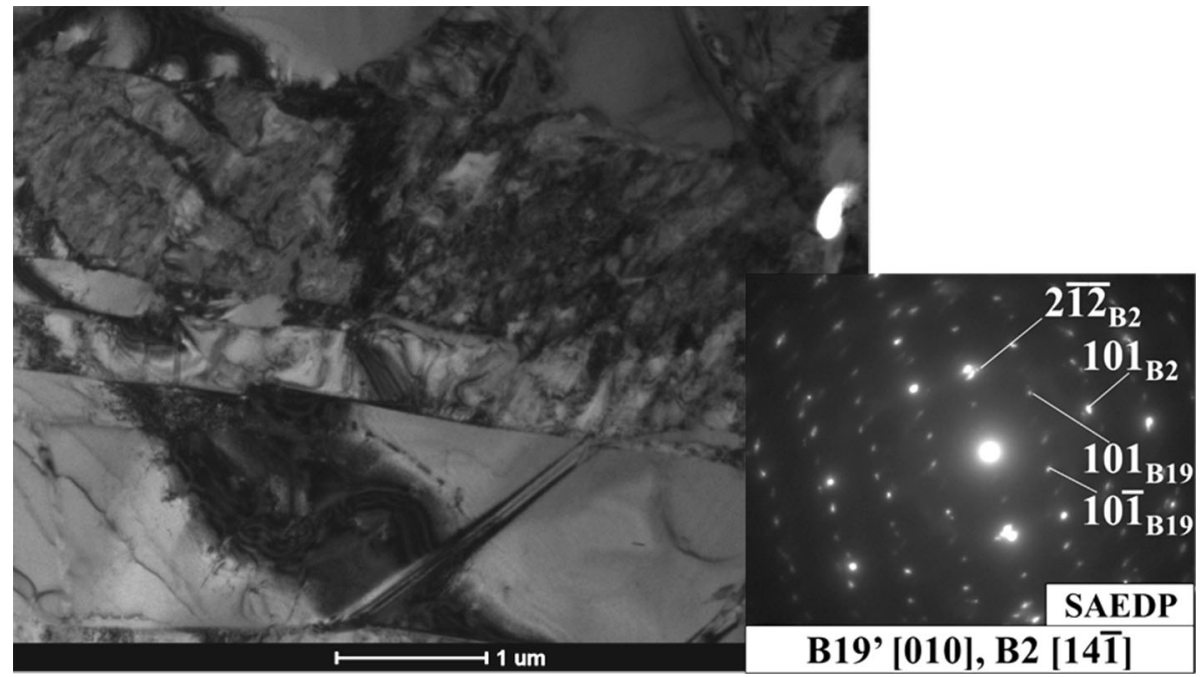

Fig. 9 BF-TEM microstructure of as-deposited NiTi produced with EBAM method and SAEDP showing crystallographic relationship between parent B2 austenite and B19' martensite

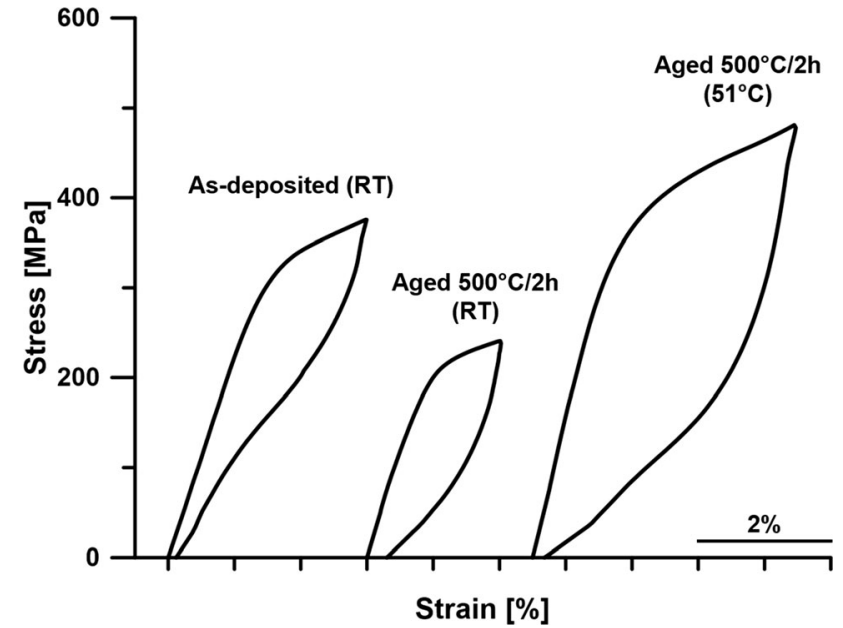

Fig. 10 Compression stress-strain curves from LENS-deposited NiTi samples in as-deposited and aged at $500{ }^{\circ} \mathrm{C} / 2 \mathrm{~h}$, tested at RT and $51{ }^{\circ} \mathrm{C}$ as marked in brackets

both material; however, this effect is observable at slightly higher temperature.

\section{Conclusions}

1 Samples fabricated using AM techniques showed diffuse DSC peaks from martensitic and reverse transformations in as-deposited state, which resulted from inhomogeneity of chemical composition and differences in grain size. Maximum peaks from martensitic transformation occurred at $-26.2{ }^{\circ} \mathrm{C}$ and $-19.2{ }^{\circ} \mathrm{C}$, for elements fabricated using LENS and EBAM techniques, respectively. $M_{\mathrm{p}}$ temperature of the powder used in LENS deposition was higher than that of AM element, while in the case of EBAM technique the $M_{\mathrm{p}}$ of wire was lower, resulting from its heat treatment.

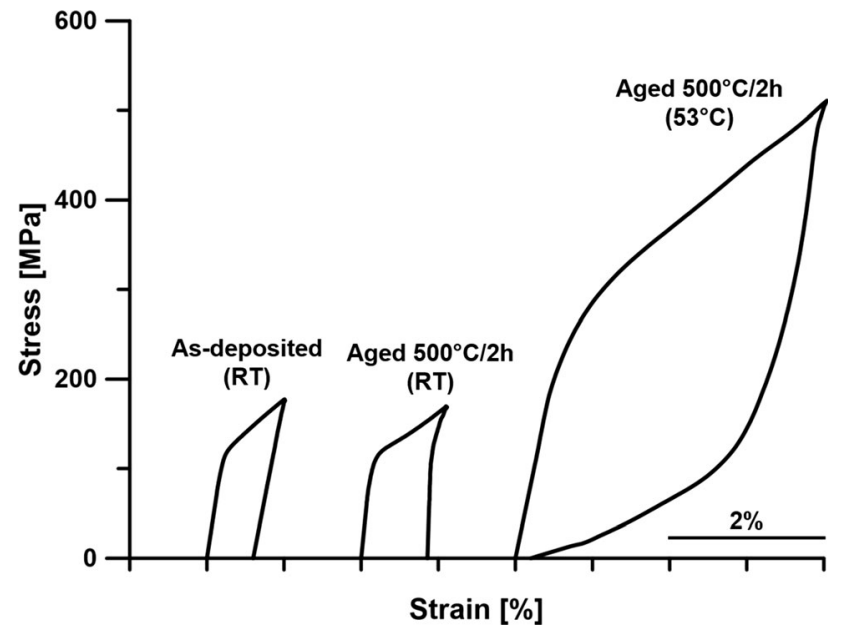

Fig. 11 Compression stress-strain curves from EBAM-deposited NiTi samples in as-deposited and aged at $500{ }^{\circ} \mathrm{C} / 2 \mathrm{~h}$, tested at RT and $53{ }^{\circ} \mathrm{C}$ as marked in brackets

2 Microstructure of deposited materials showed columnar grains of austenite, due to epitaxial growth mechanism, resulting from heat transfer direction. EBSD investigations revealed fiber axial texture $\langle 111\rangle$ in the growth direction of austenite grains. Elongated Ti-rich particles observed using TEM technique, decreased Ti content in the austenite, and were responsible for decrease of martensite transformation temperature.

3 Aging of as-deposited samples at $500{ }^{\circ} \mathrm{C}$ brought about increase in martensitic transformation temperatures, similarly to those of conventionally fabricated materials. Additional peaks coming from R-phase formation were observed on DSC cooling curves after aging at $500{ }^{\circ} \mathrm{C} /$ $2 \mathrm{~h}$ in both investigated materials.

4 Ni-Ti sample fabricated using LENS technique, in as-deposited state, revealed characteristic compression stressstrain curve for materials showing superelastic behavior. The recoverable strain reached $3 \%$ in as-deposited state at 
RT. After aging the recoverable strain decreased to $1.5 \%$ at $\mathrm{RT}$ and reach $4 \%$ at $51{ }^{\circ} \mathrm{C}$.

5 Compression curves of $\mathrm{Ni}-\mathrm{Ti}$ element fabricated using EBAM method showed merely deformed martensite characteristic. No superelastic effect was observed in as-deposited and aged samples at RT, due to $A_{\mathrm{s}}$ temperature above test temperature. Good superelastic properties $(4 \%)$ were observed in aged sample tested at $53{ }^{\circ} \mathrm{C}$.

\section{Acknowledgments}

The presented research results are the effect of the project no. UMO-2016/23/B/ST8/00754 financed by the National Science Center, Poland. The authors are grateful to $\mathrm{dr}$ A. Chandrasekaran from SMATEC Company, Belgium for valuable discussions and supplying the NiTi wire and support sheets.

\section{Open Access}

This article is licensed under a Creative Commons Attribution 4.0 International License, which permits use, sharing, adaptation, distribution and reproduction in any medium or format, as long as you give appropriate credit to the original author(s) and the source, provide a link to the Creative Commons licence, and indicate if changes were made. The images or other third party material in this article are included in the article's Creative Commons licence, unless indicated otherwise in a credit line to the material. If material is not included in the article's Creative Commons licence and your intended use is not permitted by statutory regulation or exceeds the permitted use, you will need to obtain permission directly from the copyright holder. To view a copy of this licence, visit http://creativecommons.org/licenses/by/4.0/.

\section{References}

1. M. Elahinia, N.S. Moghaddam, M.T. Andani, A. Amerinatanzi, B.A. Bimber, and R.F. Hamilton, Fabrication of NiTi Through Additive Manufacturing: A Review, Prog. Mater Sci., 2016, 83, p 630-663

2. D. Ding, Z. Pan, D. Cuiuri, and H. Li, Wire-Feed Additive Manufacturing of Metal Components: Technologies, Developments and Future Interests, Int. J. Adv. Manuf. Tech., 2015, 81(1-4), p 465481

3. T. Bormann, B. Müller, M. Schinhammer, A. Kessler, P. Thalmann, and M. de Wild, Microstructure of Selective Laser Melted NickelTitanium, Mater. Charact., 2014, 94, p 189-202

4. C. Wang, X.P. Tan, Z. Du, S. Chandra, Z. Sun, C.W.J. Lim, S.B. Tor, C.S. Lim, and C.H. Wong, Additive Manufacturing of NiTi Shape Memory Alloys Using Pre-Mixed Powders, J. Mater. Process. Technol., 2019, 271, p 152-161

5. J. Otubo, O.D. Rigo, C.M. Neto, and P.R. Mei, The Effects of Vacuum Induction Melting and Electron Beam Melting Techniques on the Purity of NiTi Shape Memory Alloys, Mater. Sci. Eng., A, 2006, 438, p 679-682

6. K.S. Kim, K.K. Jee, Y.B. Kim, W.Y. Jang, and S.H. Han, Effect of Oxidation on Transformation and Deformation Behavior in Ni-Ti Alloy, Eur. Phys. J-Spec. Top., 2008, 158(1), p 67-71

7. A. Bandyopadhyay, B.V. Krishna, W. Xue, and S. Bose, Application of Laser Engineered Net Shaping (Lens) to Manufacture Porous and Functionally Graded Structures for Load Bearing Implants, J. Mater. Sci. Mater. Med., 2009, 20(1), p 29

8. M. Węglowski, Electron Beam Rapid Prototyping Using Wires and Modification of the Surface, Manufacturing Techniques for Materials Engineering and Engineered, 1st ed., T.S. Srivatsan, T.S. Sudarshan, and K. Manigandan, Ed., CRC Press, Boca Raton, 2018, p 133-160
9. H. Meier, C. Haberland, and J. Frenzel, Structural and Functional Properties of NiTi Shape Memory Alloys Produced by Selective Laser Melting, Innovative Developments in Design and Manufacturing: Advanced Research in Virtual and Rapid Prototyping, P.J. Bartolo, Ed., Taylor \& Francis Group, Abingdon, 2012, p 291-296

10. L. Petrini and F. Migliavacca, Biomedical Applications of Shape Memory Alloys, Journal of Metallurgy, 2011, 2011, p 501483

11. A. Bansiddhi, T.D. Sargeant, S.I. Stupp, and D.C. Dunand, Porous NiTi for Bone Implants: A Review, Acta Biomater., 2008, 4, p 773782

12. M.H. Elahinia, M. Hashemi, M. Tabesh, and S.B. Bhaduri, Manufacturing and Processing of NiTi Implants: A Review, Prog. Mater Sci., 2012, 57(5), p 911-946

13. W. Maziarz, J. Dutkiewicz, J. Van Humbeeck, and T. Czeppe, Mechanically Alloyed and Hot Pressed Ni44.6Ti Alloy Showing Martensitic Transformation, Mater. Sci. Eng., A, 2004, 375, p 844-848

14. M.T. Andani, N.S. Moghaddam, C. Haberland, D. Dean, M.J. Miller, and M. Elahinia, Metals for Bone Implants. Part 1. Powder Metallurgy and Implant Rendering, Acta Biomater., 2014, 10(10), p 4058-4070

15. L. Zhang, Y.Q. Zhang, Y.H. Jiang, and R. Zhou, Superelastic Behaviors of Biomedical Porous NiTi Alloy with High Porosity and Large Pore Size Prepared By Spark Plasma Sintering, J. Alloys Compd., 2015, 644, p 513-522

16. P.C. Collins, D.A. Brice, P. Samimi, I. Ghamarian, and H.L. Fraser, Microstructural Control of Additively Manufactured Metallic Materials, Ann. Rev. Mater. Res., 2016, 46, p 63-91

17. R.F. Hamilton, B.A. Bimber, M.T. Andani, and M. Elahinia, MultiScale Shape Memory Effect Recovery in NiTi Alloys Additive Manufactured by Selective Laser Melting and Laser Directed Energy Deposition, J. Mater. Process. Tech., 2017, 250, p 55-64

18. P.R. Halani, I. Kaya, Y.C. Shin, and H.E. Karaca, Phase Transformation Characteristics and Mechanical Characterization of Nitinol Synthesized by Laser Direct Deposition, Mater. Sci. Eng., A, 2013, 559, p 836-843

19. J.M. Walker, C. Haberland, M.T. Andani, H.E. Karaca, D. Dean, and M. Elahinia, Process Development and Characterization of Additively Manufactured Nickel-Titanium Shape Memory Parts, J. Intel. Mat. Syst. Str., 2016, 27(19), p 2653-2660

20. J. Sam, B. Franco, J. Ma, I. Karaman, A. Elwany, and J.H. Mabe, Tensile Actuation Response of Additively Manufactured NickelTitanium Shape Memory Alloys, Scripta Mater., 2018, 146, p 164-168

21. T. Bormann, R. Schumacher, B. Müller, M. Mertmann, and M. de Wild, Tailoring Selective Laser Melting Process Parameters for NiTi Implants, J. Mater. Eng. Perform., 2012, 21(12), p 2519-2524

22. Y.Q. Zhang, S.Y. Jiang, Y.N. Zhao, and M. Tang, Influence of Cooling Rate on Phase Transformation and microstructure of Ti-50.9\% Ni Shape Memory Alloy, T. Nonferr. Metal. Soc., 2012, 22(11), p 26852690

23. T. Waitz, T. Antretter, F.D. Fischer, and H.P. Karnthaler, Size Effects on Martensitic Phase Transformations in Nanocrystalline NiTi Shape Memory Alloys, Mater. Sci. Tech., 2008, 24(8), p 934-940

24. A. Gyobu, Y. Kawamura, H. Horikawa, and T. Saburi, Martensitic Transformation and Two-Way Shape Memory Effect of SputterDeposited Ni-Rich Ti-Ni Alloy Films, Mater. Sci. Eng., A, 1999, 273, p 749-753

25. T.W. Duerig, K.N. Melton, D. Stöckel, and C.M. Wayman, Engineering Aspects of Shape Memory Alloys, Butterworth-Heinemann, Oxford, 2013

26. S.F. Ou, B.Y. Peng, Y.C. Chen, and M.H. Tsai, Manufacturing and Characterization of NiTi Alloy with Functional Properties by Selective Laser Melting, Metals, 2018, 8(5), p 342

27. B.V. Krishna, S. Bose, and A. Bandyopadhyay, Fabrication of Porous NiTi Shape Memory Alloy Structures Using Laser Engineered Net Shaping, J. Biomed. Mater. Res. B, 2009, 89(2), p 481-490

28. T. Honma, Effect of ageing on the spontaneous shape change and the all-round shape memory effect in Ni-rich TiNi alloy, Proceedings of the International Conference on Martensitic Transformations. ICOMAT-86, Japan Institute of Metals, 1986, 709-716

29. X. Wang, S. Kustov, and J. Van Humbeeck, A Short Review on the Microstructure, Transformation Behavior and Functional Properties of NiTi Shape Memory Alloys Fabricated by Selective Laser Melting, Materials, 2018, 11(9), p 1683

30. S. Dadbakhsh, M. Speirs, J.P. Kruth, J. Schrooten, J. Luyten, and J. Van Humbeeck, Effect of SLM Parameters on Transformation 
Temperatures of Shape Memory Nickel Titanium Parts, Adv. Eng. Mater., 2014, 16(9), p 1140-1146

31. W. Tang, B. Sundman, R. Sandström, and C. Qiu, New Modelling of the B2 Phase and its Associated Martensitic Transformation in the TiNi System, Acta Mater., 1999, 47(12), p 3457-3468

32. P.C. Collins, D.A. Brice, P. Samimi, I. Ghamarian, and H.L. Fraser, Microstructural Control of Additively Manufactured Metallic Materials, Annu. Rev. Mater. Res., 2016, 46, p 63-91

33. T. Wang, Y.Y. Zhu, S.Q. Zhang, H.B. Tang, and H.M. Wang, Grain Morphology Evolution Behavior of Titanium Alloy Components During Laser Melting Deposition Additive Manufacturing, J. Alloys Compd., 2015, 632, p 505-513

34. K. Yamauchi, I. Ohkata, K. Tsuchiya, and S. Miyazaki, Ed., Shape Memory and Superelastic Alloys: Applications and Technologies, Elsevier, Amsterdam, 2011

35. J. Khalil-Allafi, A. Dlouhy, and G. Eggeler, Ni4Ti3-Precipitation during aging of NiTi Shape Memory Alloys and its Influence on Martensitic Phase Transformations, Acta Mater., 2002, 50(17), p 42554274

36. E.R. Denlinger, J.C. Heigel, P. Michaleris, and T.A. Palmer, Effect Of Inter-Layer Dwell Time on Distortion and Residual Stress in Additive Manufacturing of Titanium and Nickel Alloys, J. Mater. Process. Technol., 2015, 215, p 123-131

37. B.A. Szost, S. Terzi, F. Martina, D. Boisselier, A. Prytuliak, T. Pirling, M. Hofmann, and D.J. Jarvis, A Comparative Study of Additive Manufacturing Techniques: Residual Stress and Microstructural anal- ysis of Clad and Waam Printed Ti-6AL-4 V Components, Mater. Des., 2016, 89, p 559-567

38. D. Chrobak and H. Morawiec, Thermodynamic Analysis of The Martensitic Transformation in Plastically Deformed NiTi Alloy, Scr. Mater., 2001, 5(44), p 725-730

39. D. Chrobak, D. Stróż, and H. Morawiec, Effect of Early Stages of Precipitation and Recovery on the Multi-Step Transformation in Deformed and Annealed Near-Equiatomic NiTi Alloy, Scr. Mater., 2003, 48(5), p 571-576

40. H. Morawiec, D. Stróż, and D. Chrobak, Effect of Deformation and Thermal Treatment of NiTi Alloy on Transition Sequence, J. Phy. IV, 1995, 5(C2), p C2-205

41. S. Saedi, A.S. Turabi, M.T. Andani, C. Haberland, H. Karaca, and M. Elahinia, The Influence of Heat Treatment on the Thermomechanical Response of Ni-Rich NiTi Alloys Manufactured by Selective Laser Melting, J. Alloys Compd., 2016, 677, p 204-210

42. N.S. Moghaddam, D.E. Saghaian, A. Amerinatanzi, H. Ibrahim, P. Li, G.P. Toker, H.E. Karaca, and M. Elahinia, Anisotropic Tensile and Actuation Properties of NiTi Fabricated with Selective Laser Melting, Mater. Sci. Eng., A, 2018, 724, p 220-230

Publisher's Note Springer Nature remains neutral with regard to jurisdictional claims in published maps and institutional affiliations. 